\title{
Mucinous cystic neoplasm of the liver with extrahepatic growth presenting with ascending cholangitis diagnosed by endoscopic ultrasound features: a case report
}

\author{
Tanawat Pattarapuntakul", Bancha Ovartlarnporn and Jaksin Sottisuporn
}

\begin{abstract}
Background: Mucinous cystic neoplasm of the liver with extrahepatic growth is a rare benign epithelial neoplasm of the biliary system that presents with a mass effect or is incidentally found on imaging. The tumor affects mostly the common hepatic duct, which is difficult to diagnose preoperatively by radiology, endoscopy, or cystic fluid analysis. Endoscopic ultrasound is a noninvasive tool for the evaluation of features of a cystic lesion and the extent of disease. Optimal treatment is complete tumor resection.

Case presentation: A 27-year-old Thai woman was referred to our hospital for investigation and treatment of clinical symptoms of obstructive jaundice and ascending cholangitis, as well as an unknown cause of obstruction. Multiple investigations were performed, including endoscopic retrograde cholangiography and magnetic resonance imaging. Endoscopic ultrasound showed a multiloculated cystic lesion with internal septations without communication to the bile duct, which helped to support a diagnosis of mucinous cystic neoplasm. Eventually, the pathological diagnosis made was mucinous cystic neoplasm of the bile duct. A follow-up clinical examination with imaging at 6 months revealed that the patient was asymptomatic and without recurrence.

Conclusions: We report a rare case of a patient with a large mucinous cystic neoplasm of the liver with extrahepatic growth causing biliary obstruction, which was diagnosed on the basis of endoscopic ultrasound features. Following definitive diagnosis, treatment with complete surgical resection using a multidisciplinary approach was successful.
\end{abstract}

Keywords: Mucinous cystic neoplasm of the liver with extrahepatic growth, Biliary cystadenoma, Ascending cholangitis

\section{Background}

Mucinous cystic neoplasm of the liver (MCN-L) with extrahepatic growth is a rare benign epithelial neoplasm of the biliary system. This tumor commonly originates in the intrahepatic bile duct, with less than $10 \%$ of cases occurring in the extrahepatic bile duct or gallbladder [1-3]. These tumors are found mostly in middle-aged women. The tumor usually presents with a mass effect, such as obstructive jaundice, abdominal pain, and/or

\footnotetext{
* Correspondence: tanawat_kuey@hotmail.com

NKC Institute of Gastroenterology and Hepatology, Faculty of Medicine,

Songklanagarind Hospital, Prince of Songkla University, Hatyai 90110,

Songkhla, Thailand
}

ascending cholangitis. MCN-L is often benign but with cystic tumor is complete surgical resection $[3,6]$.

We report what is to the best of our knowledge the first published case of MCN-L with extrahepatic growth in Thailand. Our patient presented with ascending cholangitis at a local hospital and was then referred to our university teaching tertiary care hospital. We needed to perform multiple procedures for investigation and biliary drainage before arriving at a definitive diagnosis and 
treatment. A literature review on investigations and management of MCN-L is included.

\section{Case presentation}

On 1 November 2016, a 27-year-old Thai woman was referred to our hospital from a local hospital with progressive jaundice, abdominal pain, and intermittent fever with chills. She had initially been treated with antibiotics, and she had seemed to recover for a few days, but the symptoms returned, and she was referred to our hospital. She was unemployed and had no history of comorbid disease, blood transfusions, intravenous drug use, or family history of viral hepatitis or liver disease. On physical examination, she appeared unwell with a high-grade fever and moderate icteric sclera. Her abdomen was soft with significant abdominal distention and mild tenderness at the epigastrium with a negative Murphy's sign; liver $10 \mathrm{~cm}$ with a firm consistency, smooth surface, and blunt edge; was shifting dullness-negative; and had no cutaneous signs of chronic liver stigmata.

Results of the patient's liver function tests were abnormal: total bilirubin $8.11 \mathrm{mg} / \mathrm{dL}$ (normal range $0.2-1.2$ $\mathrm{mg} / \mathrm{dL}$ ), direct bilirubin $7.06 \mathrm{mg} / \mathrm{dL}$ (normal range 0-0.2 $\mathrm{mg} / \mathrm{dL}$ ), aspartate aminotransferase $169 \mathrm{U} / \mathrm{L}$ (normal range 0-32 U/L), alanine aminotransferase $182 \mathrm{U} / \mathrm{L}$ (normal range 0-33 U/L), and alkaline phosphatase 992 U/L (normal range 39-117 U/L). The patient's viral hepatitis $\mathrm{B}$ and $\mathrm{C}$ profiles were negative. Magnetic resonance imaging (MRI) with magnetic resonance cholangiopancreatography (MRCP) of her abdomen had been performed at a local hospital before her referral. These images showed dilation of the left intrahepatic and common hepatic ducts with the presence of an enhancing oval-shaped filling defect $3 \times 5 \mathrm{~cm}$ in size at the common hepatic duct, which was initially suspected to be a common hepatic duct stone. She was referred to our hospital, where she underwent endoscopic retrograde cholangiopancreatography (ERCP) for removal of the stone, which was found to be a large oval-shaped filling defect in the common hepatic duct with left intrahepatic duct dilation. The stone could not be removed. A biliary double-pigtail plastic stent was successfully placed above the filling defect for biliary drainage. A second ERCP was performed for stone removal, but the lesion was fixed and could not be removed. Intraductal ultrasound was used to identify the lesion after removal failure. These images showed hypoechoic content in a large filling defect with internal septation (Fig. 1a and b). Intraductal brushing and biopsy were done, and the results were negative for malignancy.

The advanced endoscopy team thought that this lesion might be a cystic tumor, so endoscopic ultrasound (EUS) was performed, which demonstrated dilation of the intrahepatic bile duct and a thin-walled, multiseptated cystic lesion in the common hepatic duct with anechoic intracystic fluid content and without mural nodules or papillary projections (Fig. 2). Cystic fluid aspiration was done, which revealed a fluid carcinoembryonic antigen (CEA) level of $26.41 \mathrm{ng} / \mathrm{ml}$. The EUS features supported a diagnosis of cystic tumor of the bile duct.

Previous MRI with MRCP that showed an enhancing wall, multiloculated, and septated cystic lesion about 5.6 $\times 2.3 \mathrm{~cm}$ in size in the common hepatic duct, which was not communicating with the bile duct (Fig. 3a-c), was reviewed again with our abdominal radiologist.

After receiving a complete course of intravenous antibiotics and biliary drainage, the patient was clinically well with improved jaundice and fever. At her 2-week follow up, she was anorexic with abdominal distention.

The definitive treatment was complete tumor resection and left hepatectomy. Gross examination of the surgical specimen demonstrated a large, oval, thin-walled cyst in the common hepatic duct extending to the left proximal intrahepatic duct causing biliary dilation (Fig. 4). The cystic

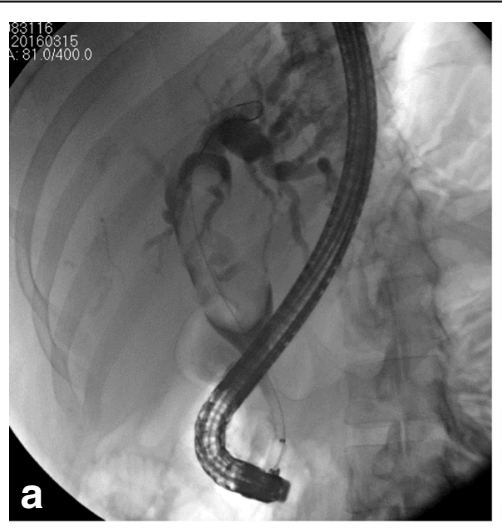

Cholangiography

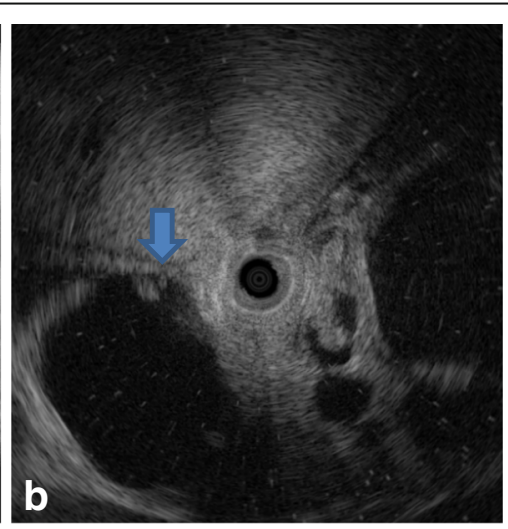

IDUS

Fig. 1 a Cholangiogram shows a large oval-shaped filling defect (arrow) in the common hepatic duct with intrahepatic duct dilation. b Intraductal ultrasound shows hypoechoic content in a large oval filling defect with internal septation 

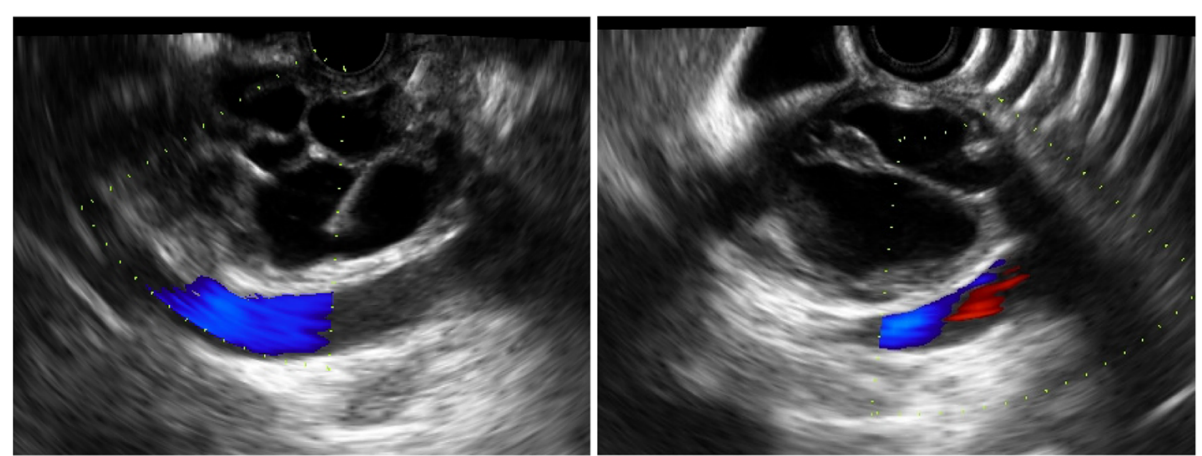

Fig. 2 Endoscopic ultrasound shows a thin-walled, multiseptated cystic lesion in the common hepatic duct and anechoic content intracystic fluid without mural nodules or papillary projections

content was clear yellowish fluid with multiseptation. Histopathology was done to confirm the diagnosis (Fig. 5).

At her 6-month follow-up after complete tumor resection, the patient was doing well, with normal liver function tests and without evidence of recurrence.

\section{Discussion}

MCN-L is a rare benign cystic neoplasm of the biliary system, with an estimated incidence of about $5 \%$ of all hepatobiliary cystic neoplasms. This cystic tumor is very rare in the extrahepatic biliary system and gallbladder $[1-3,7]$. MCN-L with extrahepatic growth can occur anywhere along the extrahepatic bile duct, most commonly in the common hepatic duct $[4,8]$. These neoplasms are usually found in middle-aged women presenting with jaundice, abdominal pain, and ascending cholangitis resulting from intraluminal tumor obstruction $[4,5]$. MCN-L is possibly hormone-dependent because it has been found to increase in size after beginning an oral contraceptive agent [8].
MCN-L with extrahepatic growth is usually a single, multiloculated cystic tumor characterized by the presence of a single layer of cuboidal or nonciliated columnar epithelium resting on a basement membrane (Fig. 5). Mesenchymal (ovarian-like) stroma is seen in $85 \%$ of cases, consisting of a thick layer of compact, spindle-shaped cells and supported by the epithelium [1-3, 9]. Biliary cystadenoma with ovarian-like stroma is considered benign with malignant potential but has a good prognosis, whereas the prognosis is less good for cases without ovarian-like stroma $[2,3,10]$. The histopathology is similar to that of mucinous cystic tumors in the pancreas and ovaries.

The majority of MCN-L cases do not communicate with the bile duct [5]. Radiological diagnosis of MCN-L is possible on transabdominal ultrasonography, contrastenhanced computed tomography (CECT)/MRI abdomen or EUS. Typical ultrasound findings are globular or ovoid, well-demarcated, noncalcified, thick-walled, multiloculated, septated internal echoes, with or without papillary projections $[8,11,12]$. On CECT studies, the

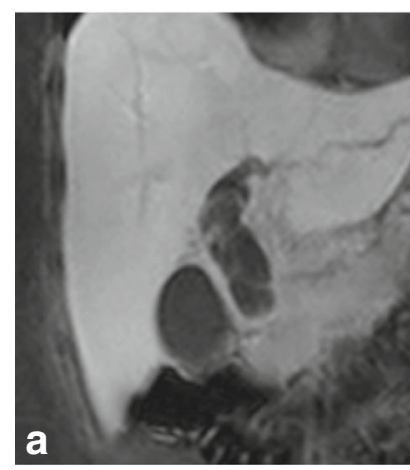

Coronal T1W

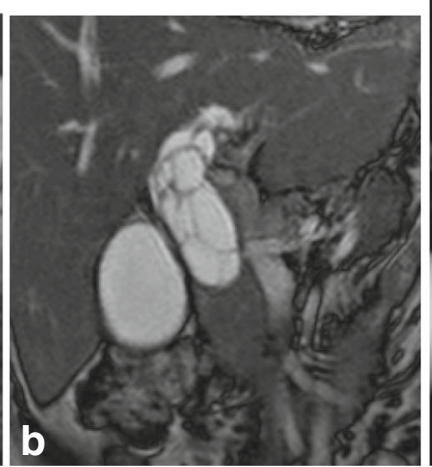

Coronal T2W

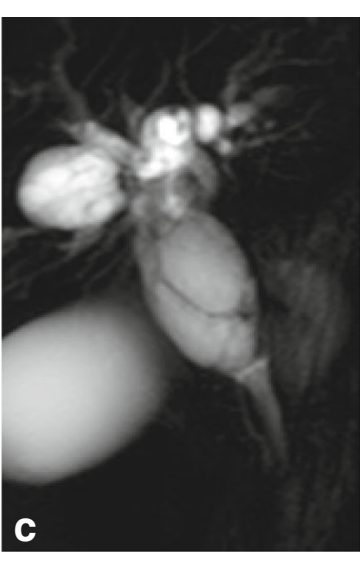

MRCP

Fig. 3 Magnetic resonance imaging $(\mathbf{a}=$ coronal T1W, $\mathbf{b}=$ coronal T2W) and magnetic resonance cholangiopancreatographic images $(\mathbf{c}=\mathrm{MRCP})$ show an enhancing wall, multiseptated cystic lesion about $5.6 \times 2.3 \mathrm{~cm}$ in size in the common hepatic duct, not communicating with the common bile duct 

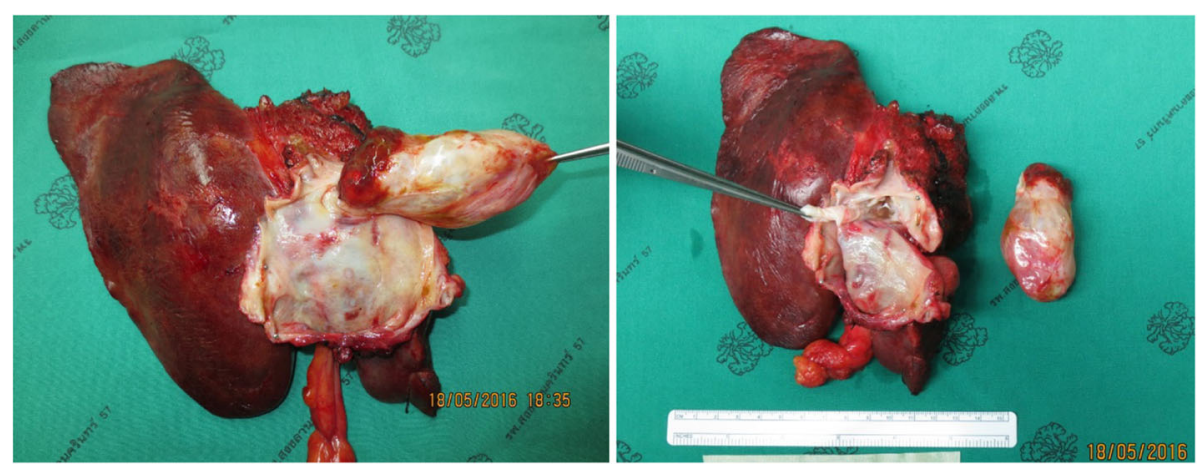

Fig. 4 Gross examination of the surgical specimen shows an oval, thin-walled cystic tumor with internal septation in the common hepatic duct. The cystic content was a clear yellowish fluid

abdomen shows multiloculated and septated intrabiliary cystic lesions with a well-defined capsule, and wall enhancement can be seen with or without calcifications [13]. MRI findings are low signaling intensity on T1weighted images and high signaling intensity on T2weighted images with enhancement of septations and cyst walls with or without calcification [14]. MRCP is used in evaluating the extent of disease and bile ducts proximal to the lesion before surgical intervention [15]. Although radiologic imaging alone cannot differentiate benign from malignant MCN-L tumors, some findings, such as irregular wall enhancement, papillary projections, and/or mural nodules, increase suspicion of malignancy $[16,17]$.

EUS is a noninvasive tool for diagnosis of MCN-L, with few reported cases of EUS features in this tumor. EUS can reveal significant features of an MCN-L, most notably a well-defined, multilocular cystic lesion with a thick-wall containing multiple septations or papillary projections, without communication between the cystic tumor and bile duct. EUS can identify mural nodules and wall irregularities more clearly than other imaging modalities, which can help predict the risk of malignancy. EUS intervention can also be used for cystic fluid aspiration and/or target wall biopsy before surgical planning $[5,6]$. A few studies have demonstrated increased levels of serum and cystic fluid tumor markers (CEA and cancer antigen 19-9), which can help to differentiate the diagnosis of MCN-L from a simple cyst, but they do not help to exclude malignancy [18]. A preoperative core needle biopsy to detect malignancy is not recommended, because this does not provide adequate information and increases the risk of needle seeding and dissemination $[1,19]$.

ERCP is useful for diagnosis and therapeutic procedures in biliary cystadenoma in patients who present with obstructive jaundice, ascending cholangitis, or hemobilia. The ERCP finding in MCN-L with extrahepatic growth is a well-demarcated filling defect with proximal bile duct dilation (obstruction) and a tumor that is not communicating with the bile duct $[5,8]$.

MCN-L with extrahepatic growth is potentially malignant, for which complete surgical resection is the treatment of choice with the lowest recurrence rate $[3,6]$. The prognosis of this tumor is excellent after complete tumor resection. Local recurrence or malignant transformation is possible and often related to incomplete resection. Follow-up with radiologic imaging is necessary.
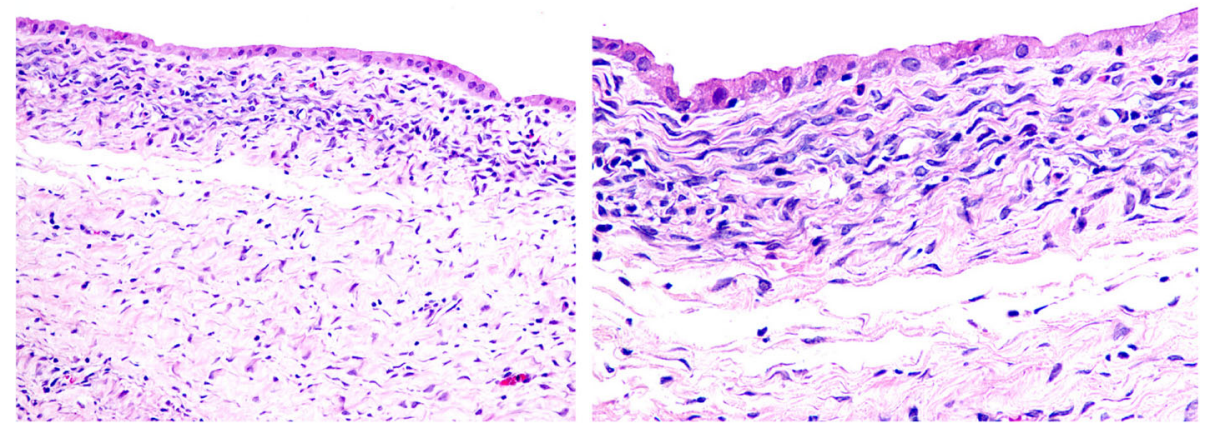

Fig. 5 Histopathological specimens show a single layer of cuboidal epithelium resting on the basement membrane and compact, spindle-shaped cells in the mesenchymal stroma (ovarian-like stroma) 


\section{Conclusions}

We report a rare case of a large MCN-L with extrahepatic growth causing biliary obstruction that was diagnosed on the basis of EUS features. Following definitive diagnosis, we were successful with complete surgical resection using a multidisciplinary approach.

\section{Abbreviations \\ CEA: Carcinoembryonic antigen; CECT: Contrast-enhanced computed tomography; ERCP: Endoscopic retrograde cholangiopancreatography; EUS: Endoscopic ultrasound; MCN-L: Mucinous cystic neoplasm of the liver; MRCP: Magnetic resonance cholangiopancreatography; MRI: Magnetic resonance imaging}

\section{Acknowledgements}

The authors thank Dr. Tortrakoon Thongkan for performing the complete tumor resection and for providing photographs of the gross specimen, as well as Dr. Teeravut Tubtawee for reviewing the MRI and MRCP imaging studies and helping us to complete the data collection for this case report.

\section{Funding}

Not applicable.

\section{Availability of data and materials}

Owing to ethical restrictions, the raw data underlying this paper are not included but are available upon request from the corresponding author.

\section{Authors' contributions}

TP was responsible for the study concept and design, data collection, discussion, conclusions, and the drafting of the manuscript. TP and BO supervised all processes of the study. JS was the endoscopist who performed the EUS and ERCP. All authors read and approved the final manuscript.

\section{Ethics approval and consent to participate}

This case report was approved, and consent for the study was provided by the ethics committee of the Faculty of Medicine, Prince of Songkla University. Written informed consent was obtained from the patient. The ethics committee's approval was based on the Declaration of Helsinki ethical principles and the International Conference on Harmonization Good Clinical Practice guideline. The ethics approval reference number is 60-060-21-3.

\section{Consent for publication}

Written informed consent was obtained from the patient for publication of this case report and any accompanying images. A copy of the written consent is available for review by the Editor-in-Chief of this journal.

\section{Competing interests}

The authors declare that they have no competing interests.

\section{Publisher's Note}

Springer Nature remains neutral with regard to jurisdictional claims in published maps and institutional affiliations.

Received: 13 June 2017 Accepted: 28 December 2017

\section{Published online: 15 February 2018}

\section{References}

1. Dixon E, Sutherland FR, Mitchell P, McKinnon G, Nayak V. Cystadenoma of the liver: a spectrum of disease. Can J Surg. 2001;44:371-6.

2. Devaney K, Goodman ZD, Ishak KG. Hepatobiliary cystadenoma and cystadenocarcinoma: a light microscopic and immunohistochemical study of 70 patients. Am J Surg Pathol. 1994;18:1078-91.

3. Soochan D, Keough V, Wanless I, Molinari M. Intra and extra-hepatic cystadenoma of the biliary duct: review of the literature and radiologic and pathological characteristics of a very rare case. BMJ Case Rep. 2012;2012: bcr0120125497. https://doi.org/10.1136/bcr.01.2012.5497.

4. Davies W, Show M, Nagorney D. Extrahepatic biliary cystadenomas and cystadenocarcinoma: report of seven cases and review of the literature. Ann Surg. 1995;222:619-25.
5. Del Poggio P, Buonocore M. Cystic tumors of the liver: a practical approach. World J Gastroenterol. 2008;14:3616-20.

6. Vogt DP, Henderson JM, Chmielewski E. Cystadenoma and cystadenocarcinoma of the liver: a single center experience. J Am Coll Surg. 2005:200:727-33.

7. Shapiro PF, Lifvendah RA. Tumors of the extrahepatic bile-ducts. Ann Surg. 1931;94:61-79.

8. Manouras A, Markogiannakis H, Lagoudianakis E, Katergiannakis V. Biliary cystadenoma with mesenchymal stroma: report of a case and review of the literature. World J Gastroenterol. 2006;12:6062-9.

9. Wheeler DA, Edmondson HA. Cystadenoma with mesenchymal stroma (CMS) in the liver and bile ducts: a clinicopathologic study of 17 cases, 4 with malignant change. Cancer. 1985;56:1434-45.

10. Ferrozzi F, Bova D, Campodonico F. Cystic primary neoplasms of the liver of the adult: CT features. Clin Imaging. 1993;17:292-6.

11. Forrest ME, Cho KJ, Shields JJ, Wicks JD, Silver TM, McCormick TL. Biliary cystadenomas: sonographic-angiographic-pathologic correlations. Am J Roentgenol. 1980;135:723-7.

12. Choi HK, Lee JK, Lee KH, Lee KT, Rhee JC, Kim KH, et al. Differential diagnosis for intrahepatic biliary cystadenoma and hepatic simple cyst: significance of cystic fluid analysis and radiologic findings. J Clin Gastroenterol. 2010;44:289-93.

13. Ahanatha Pillai S, Velayutham V, Perumal S, Ulagendra Perumal S, Lakshmanan A, Ramaswami S, et al. Biliary cystadenomas: a case for complete resection. HPB Surg. 2012;2012:501705.

14. Mortele KJ, Ros PR. Cystic focal liver lesion in the adult: differential $C T$ and MR imaging features. Radiographics. 2001;21:895-910.

15. Lewin M, Mourra N, Honigman I, Flejou JF, Parc R, Arrive L. Assessment of MRI and MRCP in diagnosis of biliary cystadenoma and cystadenocarcinoma. Eur Radiol. 2006;16:407-13.

16. Kehagias DT, Smirniotis BV, Pafiti AC, Kalovidouris AE, Vlahos L. Quiz case of the month: biliary cystadenoma. Eur Radiol. 1999;9:755-6.

17. Pojchamarnwiputh S, Na Chiangmai W, Chotirosniramit A, Lertprasertsuke N. Computed tomography of biliary cystadenoma and biliary cystadenocarcinoma. Singapore Med J. 2008;49:392-6.

18. Koffron A, Rao S, Ferrario M, Abecassis M. Intrahepatic biliary cystadenoma: role of cystic fluid analysis and surgical management in the laparoscopic era. Surgery. 2004;136:926-36.

19. Hai S, Hirohashi K, Uenishi T, Yamamoto T, Shuto T, Tanaka H, et al. Surgical management of cystic hepatic neoplasms. J Gastroenterol. 2003;38:759-64.
Submit your next manuscript to BioMed Central and we will help you at every step:

- We accept pre-submission inquiries

- Our selector tool helps you to find the most relevant journal

- We provide round the clock customer support

- Convenient online submission

- Thorough peer review

- Inclusion in PubMed and all major indexing services

- Maximum visibility for your research

Submit your manuscript at www.biomedcentral.com/submit
Biomed Central 